\title{
Flow Characteristics of Multiphase Glass Beads-Water Slurry through Horizontal Pipeline using Computational Fluid Dynamics
}

\author{
Shofique Uddin Ahmed, Rajesh Arora and Om Parkash \\ Department of Mechanical Engineering, Amity University Haryana, Gurgaon, \\ India \\ *Email: uddinshofique1991@gmail.com
}

\begin{abstract}
Over the decades conveying solid particles through pipelines is a prevalent usage for many industries like food industries, pharmaceutical, oil and gas-solid handling, power generations etc. In the present study, slurry flow through $54.9 \mathrm{~mm}$ diameter and $4 \mathrm{~m}$ long horizontal pipe with solid particle diameter $0.125 \mathrm{~mm}$ and specific gravity 2.47 has been numerically analysed using a granular version of Eulerian two-phase model and RNG K$\varepsilon$ model. The solid particles are considered as mono-dispersed in the Eulerian model. These models are available in computational fluid dynamics (CFD) fluent software package. Non-uniform structured three-dimensional mesh with a refinement near wall boundary region has been selected for discretising the flow domain, and governing equations are solved using control volume finite difference method. Simulations are conducted at velocity varying from $1 \mathrm{~m} / \mathrm{s}$ to $5 \mathrm{~m} / \mathrm{s}$ and efflux concentration varying from 0.1 to 0.5 by volume. Different slurry flow parameters such as solid concentration distribution, velocity distribution, pressure drop etc. have been analysed from the simulated results. The simulated results of pressure drop are correlated with the experimental data available in previous literature and are found to be in excellent compliance with the experimental data.
\end{abstract}

Keywords: 3D CFD modelling; Eulerian two-phase model; RNG K- $\varepsilon$ model; concentration distribution; velocity distribution; pressure drop; slurry pipeline.

\section{NOMENCLATURE}

$\mathrm{C}_{\mathrm{w}} \quad$ efflux concentration

D diameter of pipe

$\mathrm{d}_{\mathrm{s}} \quad$ particle diameter

$\boldsymbol{\nabla P} \quad$ static pressure gradient

$\mathrm{G} \quad$ acceleration due to gravity

$\vec{v} \quad$ velocity of solid phase

$\overrightarrow{v_{f}} \quad$ velocity of fluid phase

$\mathrm{C}_{\mathrm{vm}} \quad$ coefficient of virtual mass

$\rho \quad$ mass density

$\rho_{\mathrm{f}} \quad$ mass density for fluid phase $\mathrm{g}_{\mathrm{o}, \mathrm{ss}} \quad$ radial distribution function

$\mu_{\mathrm{s}} \quad$ shear viscosity for solid phase (pas)

$\mu_{\mathrm{f}} \quad$ shear viscosity for fluid phase (pas)

$\mu_{\mathrm{s}, \mathrm{col}} \quad$ collisional viscosity

$\mu_{\mathrm{s}, \mathrm{kin}} \quad$ kinetic viscosity

$\mu_{\mathrm{s}, \mathrm{fr}} \quad$ frictional viscosity

$\mathrm{C}_{\mathrm{D}} \quad$ drag coefficient

$\mathrm{e}_{\mathrm{ss}} \quad$ restitution coefficient

$\theta_{\mathrm{s}} \quad$ granular temperature

$\mathrm{I}_{2 \mathrm{D}} \quad$ second invariant strain rate tensor for solid phase 


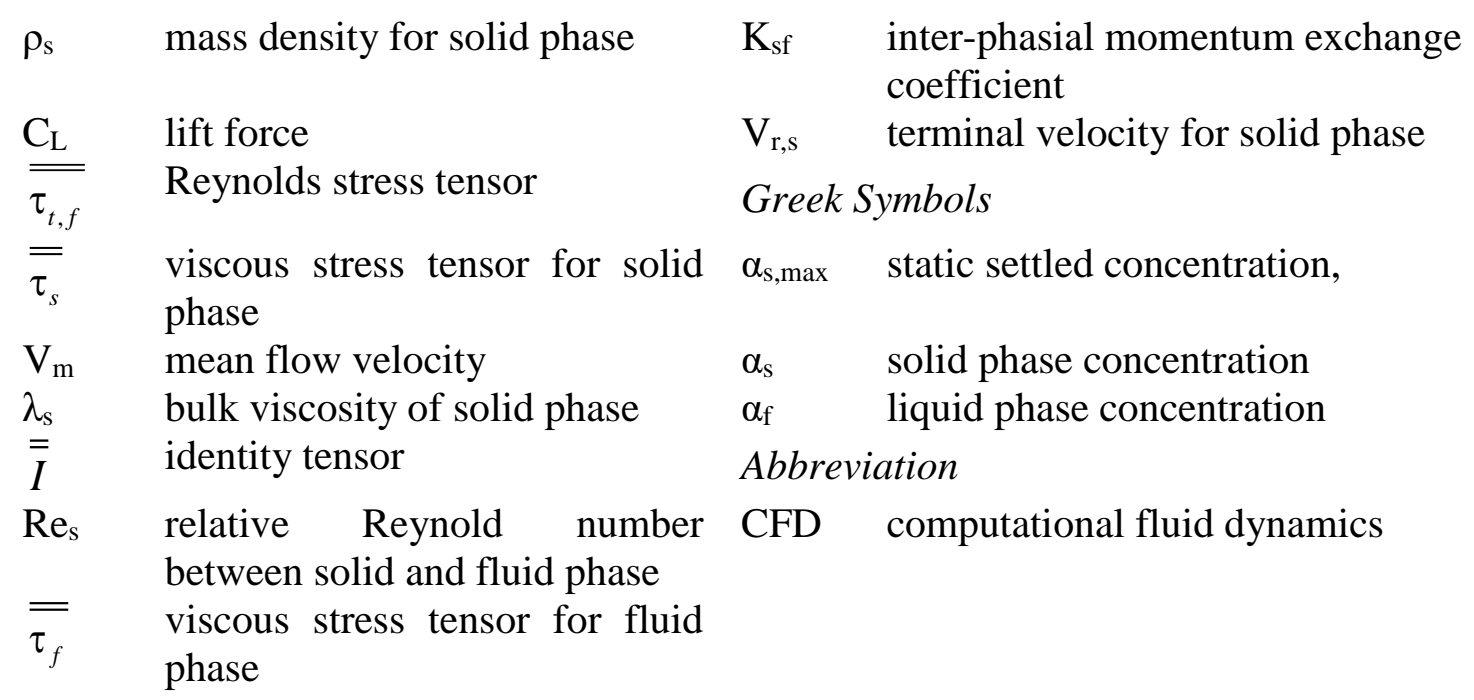

\section{INTRODUCTION}

The hydraulic transfer of solid materials through pipelines has been used industrially for a long time. Over the decades conveying solid particles through pipelines has been prevalent usage for many industries such as food industries, pharmaceutical, oil and gas, solid handling, power generations etc. this mode of conveyance has many advantages over the conventional way of transportations. It reduces air pollution, road traffic, noise pollution, accidents etc. Study of Link, Faddick, and Lavingia [1] suggested that the conveyance of solid through pipelines over a long distance is comparatively more efficient than the traditional way of conveyance. In many industries, the waste product disposal is carried out by this process. In thermal power plants, the waste products such as fly ash, bottom ash and other after burnt products are disposed of by using this method. To study the transportation of solid particles through the pipeline it is necessary to have an idea about the velocities of fluid and solid particles at different locations of the pipeline. To have an efficient and smooth flow of the slurry accurate predictions of slurry transport properties such as flow velocity, solid particle concentrations, pressure drops etc. are required. The study of different flow parameters is required for a better prediction of the exclusive slurry flow prediction and for the adaptation of optimum design for the pipe. Different models have been developed over the years to illustrate the behaviour of flow parameters of the slurry flow regimes. Slurry flow through pipes is the process where solid particles are mixed with a fluid and this mixture also known as the slurry is made to flow through the pipe. The solid particles concentrations in the mixture vary according to the flow conditions. Generally, the slurry flow regime can be categorized into a stationary bed, moving bed, heterogeneous, homogenous and saltation flow regime. Among all these flow regimes the most occurring is heterogeneous flow regime because no flow regime can be perfectly homogenous.

Computational fluid dynamics (CFD) is a sophisticated approach by which wide range of flow problems can be solved. This approach is being widely used for numerical investigation of various multiphase flow problems. Advantages of this approach include the ability to solve various 3D slurry flow problems under various flow conditions with different flow models which could have been almost impossible with experimental methods. There are relatively few numerical investigations using CFD to predict the behaviour of flow parameters in the slurry flow. Disregarding many obstructions CFD is an effective technique for intriguing various slurry flow problems in horizontal pipes as 
well as predicting its behaviours due to variations of different flow parameters. It comforts the analyst in comprehensive numerical studies with greater prosperity and low costs moreover it provides exclusive enlightenment about the local variation of different flow variables within the fluid domain. A wide range of experimental works on slurry flow in the horizontal pipe has been executed over the years which give wide scope for numerical simulation of the slurry flow characteristics by using CFD technique.

Since the third decades of $20^{\text {th }}$ century researchers are focusing towards establishing an accustomed solution for concentration profile, pressure drop and deposition velocities for sophisticated prediction of slurry flow. Initial studies in this extent include the study of O'Brien [2] and Rouse [3]. They envisioned solid particle diffusion in a gravity-based open channel flow containing a very low volumetric concentration of solid particles using a diffusion model. After that, many types of research have been performed aiming for the solid particle distribution for the slurry flows [4-16]. Further studies have taken place on the slurry flow pressure drop over the pipe length. [17-23]. Pressure-driven slurry flow of heavy oil in the horizontal pipeline was investigated experimentally and numerically by Zambarno et al. [24], in their study particle size was taken as $500 \mu \mathrm{m}$ and mean slurry velocities as $0.2-2.3 \mathrm{~m} / \mathrm{s}$. The behaviour of flow velocities and efflux concentration along with some other important flow parameters such as mean slurry friction coefficient was studied. Singh et al. [25] studied the erosion wear behaviour of slurry flow in a $90^{\circ}$ bend considering suspended solid particles by using CFD technique. In their study, the erosion wear was simulated to examine the impact of miscellaneous flow parameters like particle concentration, flow velocity and particle size.

A two-phase Eulerian model was selected for studying the erosion of solid particles at pipe bend. A standard K-epsilon turbulence energy model was adopted for flow simulation of solid-fluid through the pipe. Wang et al. [26] performed a combined investigation of numerical, analytical and experimental methods to analyse the distribution of velocity, solid particle concentration and pressure drop in an ice-water slurry flow. An investigative study for prediction of flow velocity behaviour and erosioncorrosion of a $90^{\circ}$ horizontal pipe elbow was implemented by Liu et al. [27]. From their work, they predicted that erosion-corrosion rate is raised most when fluid velocity increases from 3.5-4 m/s. Kaushal et al. [28] performed a numerical investigation of mono dispersed glass-water slurry flow at high concentrations. $125 \mu \mathrm{m}$ glass beads were taken as solid particles, varying the velocity of the fluid to $3.5 \mathrm{~m} / \mathrm{s}$ and solid concentrations to $50 \%$. The behaviour of solid concentration, flow velocity and pressure drop were predicted in their study. Chen et al. [29] performed a CFD numerical simulation of slurry flow consisting of solid-liquid slurry in the horizontal pipeline, RNG k-epsilon model was adopted for modelling the turbulent two-phase flow. The consequences of total solid particle concentration, flow velocity and grain compositions were predicted from their simulated results. Lin and Ebadian [30] studied the slurry flow containing sand and water in the horizontal pipe by adopting RNG K-epsilon model along with 3-D ASM model. They predicted the behaviour of density distribution; mean skin friction coefficient distributions, pressure drop, mean velocity profiles and volume fraction in their study. Nabil et al. [31] developed a derived 2D model by adopting Eulerian and K-epsilon model for slurry flow using CFD technique to predict the behaviour of various slurry flow parameters and their effects for definite particle size. Gopaliya and Kaushal [32] performed a 3D CFD analysis of slurry flow consisting of sand and water through horizontal pipe considering various particle sizes. They predicted different slurry flow 
parameter behaviours such as solid particle velocity distribution, turbulent viscosity, pressure drop, particle concentration, granular pressure and their effects.

A two-fluid model for predicting the important flow parameters characteristics viz. Pressure gradient, solid volume fraction, velocity distribution in a completely drooping slurry flow through the horizontal pipeline of diameter $50-150 \mathrm{~mm}$ was analysed by Messa et al. [33]. On the other hand, the particle size between $90-520 \mu \mathrm{m}$ with a solid concentration of up to $40 \%$ by volume and velocity 1 to $7 \mathrm{~m} / \mathrm{s}$ was considered by Gopaliya and Kaushal [34]. They investigated for predicting the consequences of grain size on different sand-water slurry flow variables. In their study, they adopted the Eulerian model with RNG K-epsilon model to analyse the dispersed solid particles of different grain size. They predicted that pressure gradient surges at higher volumetric concentration for all particle sizes. Slurry flow behaviour through the horizontal pipeline was investigated by Ekabama et. al [35] using the CFD technique. In their study, they considered volume concentration of $8-45 \%$, the particle size of $90-500 \mu \mathrm{m}$ with a flow velocity of 1.5 to5.5 $\mathrm{m} / \mathrm{s}$. From their study, they concluded that the solid particle distribution is asymmetrical in vertical plane and rate of asymmetrical nature increases at larger solid particles. Kaushal et al. [36] analysed the slurry flow characteristics considering the solid particles as mono-dispersed in a horizontal pipe bend by using both CFD technique and experimental method. In their study narrow silica sand of particle diameter $450 \mu \mathrm{m}$ with efflux, solid particle concentration up to $16.28 \%$ and velocity up to $3.56 \mathrm{~m} / \mathrm{s}$ was considered.

Derrick et al. [37] predicted the behaviour of erosion in pipe bend by using suspended diffused particles. They studied the solid particle erosion on pipe bend considering four different pipe bends by using CFD technique. Bartosik [38] developed two and three parameters Rheological model for analysing the turbulent slurry flow. The purpose of his work was to compare the prediction of velocity distributions and frictional head loss. Fulran et al. [39] developed an A-scan ultrasonic technique to measure solid particle distributions in soda-lime glass-water slurry flow with $0.195 \mathrm{~mm}$ particle size. The results achieved by using this experimental technique were compared with CFD simulation results. The comparison of results showed that the ultrasound technique is useful in characterising slurry flow containing high concentrations. Peng and Cao [40] developed Eulerian-Lagrangian numerical model which was two way coupled for anticipating the effects of solid particle erosion in bends of pipes for a two-phase solidfluid slurry flow. From their study, they predicted the influence of different flow parameters viz. particle mass flow, bending angle, flow velocity and pipe diameter on erosion. Chandel et al. [41] performed a numerical analysis of high concentration coal ash slurry through horizontal pipelines by using CFD technique. In their study, they adopted Eulerian two-phase model and mixture model for simulation of the flow. They considered particle size of $85 \mu \mathrm{m}$ with a flow velocity of $3.3 \mathrm{~m} / \mathrm{s}$ and solid efflux concentration ranging from $50-70 \%$ by weight. Pressure gradient was predicted using both the models per $100 \mathrm{~m}$ length of pipe. They concluded that the Eulerian approach presumes the pressure gradient accurately at all efflux concentrations and flow velocities. Onokoko et al. [42] conducted an experimental and CFD analysis of ice-water two-phase slurry flow characteristics in a long horizontal pipe. They investigated pressure drop in the pipe, outlet and inlet densities, temperature and mass flow rates of the ice slurry from their experimental setup. A CFD simulation was carried out for the same by developing a numerical model.

In this study, 3D local concentration distribution of solid particles, pressure distribution and velocity distributions are analysed by adopting the Eulerian model in the 
horizontal pipe with pipe diameter $54.9 \mathrm{~mm}$. The length of the pipe is taken as $4 \mathrm{~m}$, which is longer than 50D length required for completely developed flow. Glass beads -water slurry is considered with glass particle mean diameter of $125 \mu \mathrm{m}$ and specific gravity 2.47 , for a flow velocity ranging from $1 \mathrm{~m} / \mathrm{s}$ to $5 \mathrm{~m} / \mathrm{s}$ and efflux concentration up to $50 \%$ by volume (viz. 10\%, 20\%, 30\%, 40\% and 50\%). Glass beads particles are considered as mono-dispersed. The 3D simulated result of pressure drop is correlated with the data available in previous experimental work by Kaushal and Tomita [18].

\section{MATHEMATICAL MODEL}

It is essential for all numerical analysis to adopt and develop a proper mathematical model keeping in view the objectives and physics of the problem. Slurry flow through the pipeline is a multiphase flow problem (solid-fluid). Several multiphase models such as the discrete phase, mixture model and Eulerian model are used for mathematical modelling of slurry flow problems. The selection of a specific model relies upon the solid particle efflux concentration. Slurry flow not being a diffused dilute system, the available discrete model could not be applied to analyse the flow. Therefore, the Eulerian model, as well as Mixture model, can be used in the current study. But based on literature survey the Eulerian model is adopted for the present study as the Eulerian model satisfies both laws of conservation of momentum and mass for solid phase and liquid phase separately. The granular Eulerian model is preferred over the non-granular version because the nongranular version does not provide the option for considering the collision and friction among solid particles, which is essential in the slurry flow. The granular version of Eulerian model adopted for this current analysis is described.

\section{Eulerian Model}

The Eulerian model does not distinguish between fluid-fluid and solid-fluid multiphase flows. In the Eulerian model, it is assumed that the slurry flow comprises a separate fluid and solid phases, and they structure a continuum so that the volume concentration of $\operatorname{solid}\left(\alpha_{s}\right)$ and fluid $\left(\alpha_{f}\right)$ is equal to 1 . i.e. $\alpha_{s}+\alpha_{f}=1$. This model satisfies both law of conservation of mass and momentum for solid phase and liquid phase individually. The forces acting on each particle in the slurry comprises of:

i. Static/solid pressure gradients, $\nabla$ P/VPs.

ii. Forces due to the difference in velocities of two phases, $K_{s f}\left(\vec{v}_{s}-\vec{v}_{f}\right)$

iii. Viscous and body forces, $\nabla \cdot \overline{\overline{\tau_{f}}}$ and $\rho \overrightarrow{\mathrm{g}}$, where $\overline{\overline{\tau_{f}}}$ represents the stress tensor of fluid, $\rho$ denotes the mass density and $\mathrm{g}$ is gravitational acceleration.

iv. Lift/virtual mass forces. The coefficient of virtual mass/ lift forces, $C_{L} / C_{v m}$ are assumed to be 0.5 .

v. The particles in the analysis are assumed to be fluid in nature.

The following governing equations are taken from Kaushal and Tomita [18].

\section{Continuity equation}

$\nabla \cdot\left(\alpha_{t} \rho_{t} \vec{v}_{t}\right)=0, t$ being either solid or fluid. 
Momentum equation for fluid phase

$$
\begin{aligned}
& \nabla \cdot\left(\alpha_{\mathrm{f}} \rho_{\mathrm{f}} \overrightarrow{\mathrm{v}}_{\mathrm{f}} \overrightarrow{\mathrm{v}}_{\mathrm{f}}\right)=-\alpha_{\mathrm{f}} \nabla \mathrm{P}+\nabla \cdot \overline{\overline{\tau_{f}}}+\alpha_{\mathrm{f}} \rho_{\mathrm{f}} \overrightarrow{\mathrm{g}}+\mathrm{K}_{\mathrm{sf}}\left(\overrightarrow{\mathrm{v}_{\mathrm{s}}}-\overrightarrow{\mathrm{v}_{\mathrm{f}}}\right)+\mathrm{C}_{\mathrm{vm}} \alpha_{\mathrm{f}} \rho_{\mathrm{f}}\left(\overrightarrow{\mathrm{v}_{\mathrm{s}}} \cdot \nabla \overrightarrow{v_{\mathrm{s}}}-\overrightarrow{\mathrm{v}_{\mathrm{f}}} \cdot \nabla \overrightarrow{v_{\mathrm{f}}}\right) \\
& +C_{\mathrm{L}} \alpha_{\mathrm{s}} \rho_{\mathrm{f}}\left(\vec{v}_{\mathrm{f}}-\vec{v}_{\mathrm{s}}\right) \times\left(\nabla \times{\overrightarrow{v_{f}}}\right)
\end{aligned}
$$

Momentum equation for solid phase

$$
\begin{aligned}
& \nabla \cdot\left(\alpha_{s} \rho_{s} \vec{v}_{s} \vec{v}_{s}\right)=-\alpha_{s} \nabla P-\nabla P_{s}+\nabla \cdot \overline{\overline{\tau_{s}}}+\alpha_{s} \rho_{f} \vec{g}+K_{s f}\left(\overrightarrow{v_{f}}-\overrightarrow{v_{s}}\right)+C_{v m} \alpha_{s} \rho_{f}\left(\overrightarrow{v_{f}} \cdot \nabla \overrightarrow{v_{f}}-\right. \\
& \left.\overrightarrow{v_{s}} \cdot \nabla \overrightarrow{v_{s}}\right)+C_{L} \alpha_{s} \rho_{f}\left(\vec{v}_{s}-\vec{v}_{f}\right) \times\left(\nabla \times \overrightarrow{v_{f}}\right)
\end{aligned}
$$

Where $\overline{\overline{\tau_{f}}}$ and $\overline{\overline{\tau_{s}}}$ are the stress tensors for fluid and solid respectively, represented as,

$$
\overline{\overline{\tau_{s}}}=\alpha_{\mathrm{s}} \mu_{\mathrm{s}}\left(\nabla \overrightarrow{v_{\mathrm{s}}}+\nabla \vec{v}_{\mathrm{s}}^{\mathrm{tr}}\right)+\alpha_{\mathrm{s}}\left(\lambda_{\mathrm{s}}-\frac{2}{3} \mu_{\mathrm{s}}\right) \nabla \cdot \overrightarrow{\mathrm{v}_{\mathrm{s}}} \overline{\overline{\mathrm{I}}}
$$

Where 'tr' indicates transpose and $\overline{\bar{I}}$ is the identity tensor, $\lambda_{s}$ is the bulk velocity of solid, represented as:

$$
\lambda_{\mathrm{s}}=\frac{4}{3} \alpha_{\mathrm{s}} \rho_{\mathrm{s}} \mathrm{d}_{\mathrm{s}} \mathrm{g}_{\mathrm{o}, \mathrm{ss}}\left(1+\mathrm{e}_{\mathrm{ss}}\right)\left(\frac{\theta_{\mathrm{s}}}{\pi}\right)^{\frac{1}{2}}
$$

Where, $\theta_{\mathrm{s}}=-\frac{\mathrm{K} \theta_{\mathrm{s}}}{\gamma} \frac{\partial \theta_{\mathrm{s}}}{\partial \mathrm{n}}+\frac{\sqrt{3} \Pi \Phi \rho_{\mathrm{s}} \alpha_{\mathrm{s}} \mathrm{v}_{\mathrm{s}}^{2} \mathrm{~g}_{\mathrm{o}, \mathrm{s}} \theta_{\mathrm{s}}^{3 / 2}}{6 \alpha_{\mathrm{s}, \max }}$, and $d_{s}$ is the diameter of solid particles. In this study, taken as $125 \mu \mathrm{m}$.

\section{Turbulent model for fluid phase}

The turbulent model of the fluid phase is calculated by using the RNG K- $\varepsilon$ model along with other additional conditions causing interfacial turbulent momentum transfer. The fluid phase Reynolds stress tensor is given by:

$$
\overline{\overline{\tau_{t, f}}}=-\frac{2}{3}\left(\rho_{f} k_{f}+\mu_{t, f} \nabla \vec{v}_{f}\right) \overline{\bar{I}}+\mu_{t, f}\left(\nabla \vec{v}_{f}+\nabla \vec{v}_{f}^{t r}\right)
$$

Here $\mu_{t, f}$ is the turbulent viscosity. An analytical differential correlation for turbulent viscosity is provided with RNG K- $\varepsilon$ model for modelling the flow at lower Reynolds number. At high Reynolds number (which is the case in currthe ent study) this analytical correlation converts to:

$$
\mu_{\mathrm{t}, \mathrm{f}}=\rho_{\mathrm{f}} C_{\mu} \frac{\mathrm{k}_{\mathrm{f}}^{2}}{\varepsilon_{\mathrm{f}}}, \text { With } C_{\mu}=0.09
$$

Both RNG $k-\varepsilon$ approach and standard $k-\varepsilon$ approach anticipates the turbulent kinetic energy $k_{f}$ and turbulent energy dissipation rate $\varepsilon_{f}$ almost in simia lar way. RNG and standard $k$ $\varepsilon$ approach differ in such a fashion that RNG $k-\varepsilon$ model contains a supplementary term in the $\varepsilon$ equation: 


$$
\mathrm{R}_{\varepsilon}=\frac{\mathrm{C}_{\mu} \rho \eta^{3}\left(1-\eta / \eta_{0}\right) \varepsilon^{2}}{\left(1+\beta \eta^{3}\right) \mathrm{k}}
$$

Where, $\eta_{0}=4.38, \beta=0.012, \eta=\mathrm{Sk} / \varepsilon$. The constant parameters are taken as $\mathrm{C}_{\mu \mathrm{m}}=0.0845, \mathrm{C}_{1 \varepsilon}=1.42, \mathrm{C}_{2 \varepsilon}=1.68, \mathrm{C}_{3 \varepsilon=1.3} \quad \sigma_{\mathrm{k}}=0.75, \sigma_{\varepsilon}=1.2$.

\section{Turbulent model for solid phase}

The turbulence behaviour of the solid phase is portended from Tchen's theory in Lun et al [43]. In this theory turbulent kinetic energy, dispersion coefficients and correlation functions of the solid phase are calculated using continuous turbulent motions of the fluid phase. The time scale considering inertial effects acting on the particle is represented as:

$$
\tau_{\mathrm{F}, \mathrm{sf}}=\alpha_{\mathrm{s}} \rho_{\mathrm{f}} \mathrm{K}_{\mathrm{sf}}^{-1}\left(\frac{\rho_{\mathrm{s}}}{\rho_{\mathrm{f}}}+\mathrm{C}_{\mathrm{vm}}\right)
$$

The characteristic time of correlated turbulent motion or eddy particle interaction time is given by:

$$
\begin{aligned}
& \tau_{\mathrm{t}, \mathrm{f}}=\tau_{\mathrm{t}, \mathrm{f}}\left[1+\mathrm{C}_{\beta} \zeta^{2}\right]^{\frac{1}{2}} \\
& \xi=\frac{\left|\vec{V}_{r}\right|}{\sqrt{\frac{2}{3} K_{f}}}
\end{aligned}
$$

The characteristic time for energetic turbulent eddies is given by:

$$
\tau_{\mathrm{t}, \mathrm{f}}=\frac{3}{2} C_{\mu} \frac{\mathrm{k}_{\mathrm{f}}}{\varepsilon_{\mathrm{f}}}
$$

$\left|\vec{V}_{\mathrm{r}}\right|$ is the average value of local relative velocity between the particle and surrounding fluid defined as the difference in slip and drift velocity.

$$
\overrightarrow{\mathrm{V}}_{\mathrm{r}}=\overrightarrow{\mathrm{v}}_{\mathrm{sf}} \overrightarrow{\mathrm{v}}_{\mathrm{dr}}
$$

\section{Wall functions}

Collection of semi-empirical functions and formulae are defined as wall functions. Wall functions help in achieving better results near the wall boundary. So the near-wall region needs special treatments during the analysis because of the presence of high gradient parameters in this problem. This is achieved by refining the meshing at near-wall boundary using the standard wall function treatment option available in RNG K- $\varepsilon$ model. 


\section{NUMERICAL SOLUTIONS}

\section{Solution Methods and Convergence Criteria}

In this present study second order upwind discretisation scheme is chosen for turbulent kinetic energy, momentum equation and turbulent dissipation energy and first-order upwind discretisation scheme is selected for volume fraction. Application of these schemes confirms better stability, accuracy and convergence of the flow problem. Moreover, decreasing the value of under-relaxation factors ensures better convergence of the problem. URF (under-relaxation factor) for volume fraction has been reduced to 0.3 from 0.5 and for momentum it has been reduced from 0.7 to 0.5 . Other parameters are kept as default. Convergence of the problem depends on the scaled residual. For this flow problem, the residuals contain continuity, X-velocity, Y-velocity, Z-velocity for both the phases $\mathrm{k}$ and $\varepsilon$ for phase 1 and volume fraction for phase 2, which need to be converged at some specific region. In this present study, an extension of a SIMPLE algorithm for multiphase flow problem (phase coupled SIMPLE algorithm) is used for pressure and velocity coupling.

\section{Geometry and Mesh}

A pipe of $54.9 \mathrm{~mm}$ diameter and $4 \mathrm{~m}$ length is created in ANSYS Workbench design modular. Mesh is generated in workbench by using the multizone method with hexa core elements. 12 inflation layers with the size of $0.03 \mathrm{~mm}$ and smooth transition have been introduced to refine the mesh near the wall boundary. The mesh contains 3820224 elements. (Figure 1)

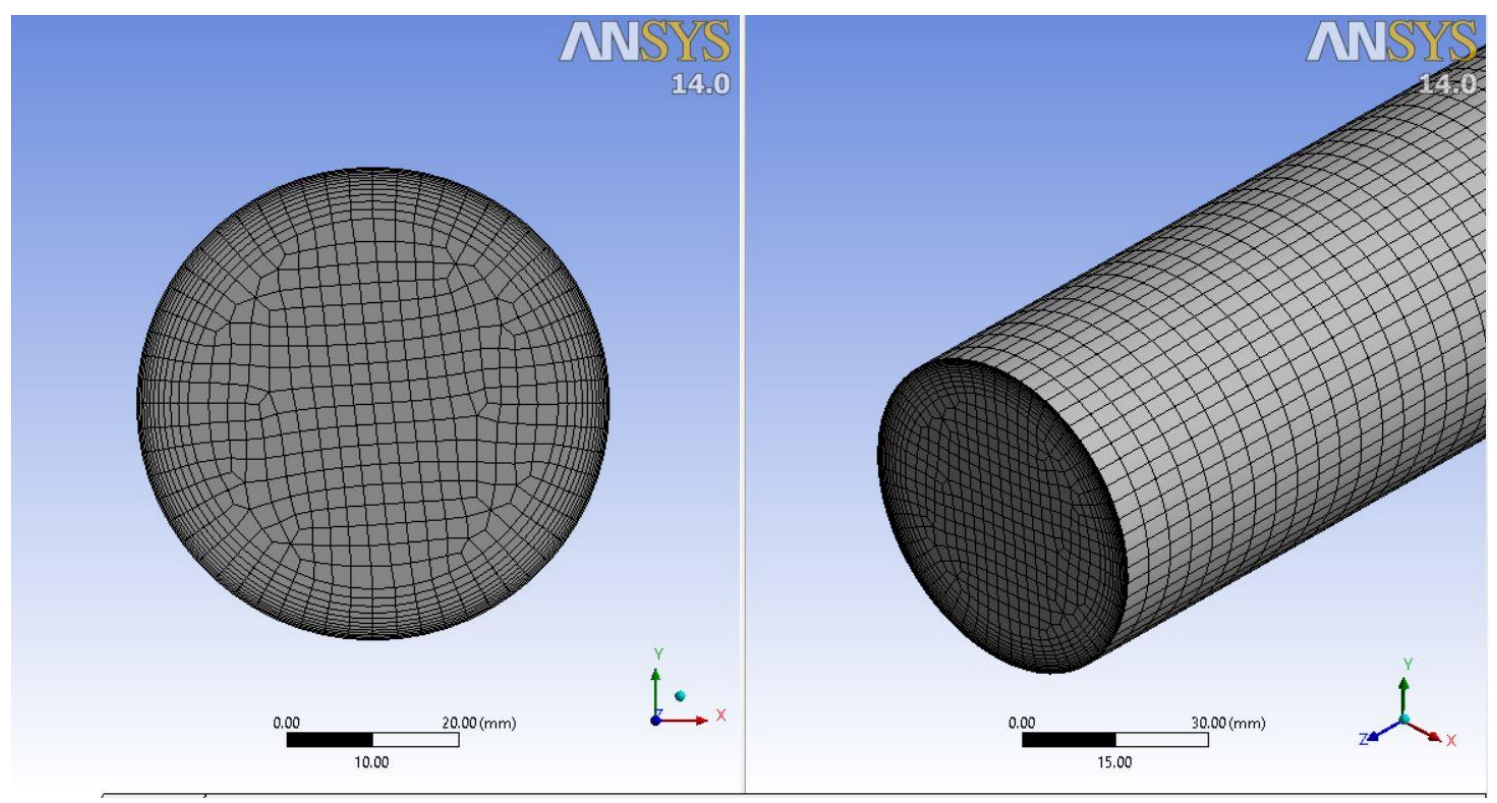

Figure 1. View of mesh used in this study.

\section{Boundary Conditions}

Three boundary conditions namely outlet boundary, wall boundary and inlet boundary, are applied in the computational fluid domain. Velocity and solid particles efflux 
concentration (volume fraction) have been introduced for solid phase, and velocity is introduced for the fluid phase at the inlet boundary i.e. $V_{m}=v_{s}=v_{f}$ and $\alpha_{s}=C_{v f}$ and $\alpha_{\mathrm{f}}=1-\alpha_{\mathrm{s}}$ Where $C_{\mathrm{vf}}$ is the solid particle efflux concentration. No slip boundary conditions are used at the wall to predict the solid and fluid velocity at the wall. In this study for predicting the concentration profiles and velocity distributions a completely developed flow at the pipe outlet is used.

\section{Grid Independency Test}

In numerical simulations, it is highly recommended to adopt an optimal mesh for better prediction of the flow characteristics with minimal error. For this reason, a grid test has been conducted to adopt the optimal mesh for the final calculation. In this test five mesh with different number of elements 95000, 150000, 201000, 310000 and 387000 have been introduced. Using these meshes, the problem has been simulated applying same boundary conditions (velocity $=5 \mathrm{~m} / \mathrm{s}$ and $\mathrm{C}_{\mathrm{vf}}=0.1$ ) for all mesh and velocity profile is drawn for each mesh. Plots are shown in Figure 2.

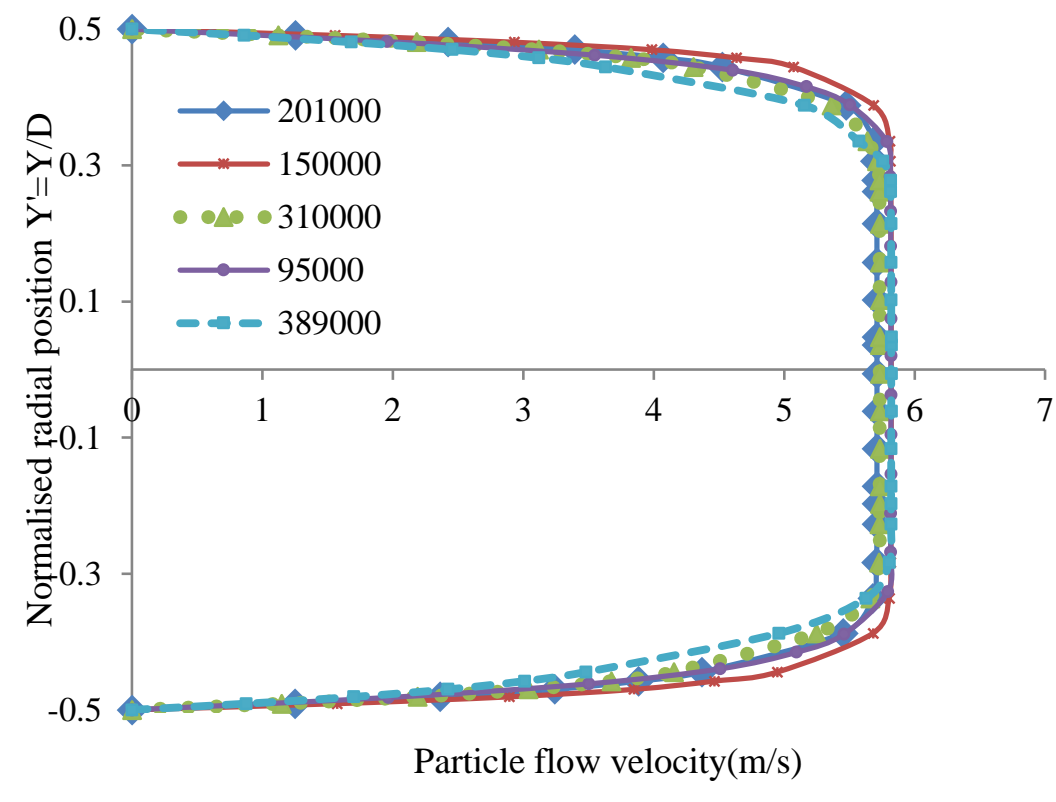

Figure 2. Plot of grid independency test results.

It is confirmed from the above plot that the velocity profile of the mesh containing 201000 elements and the mesh containing 310000 elements are super imposing with each other. So, the mesh containing 201000 elements has been considered as optimal mesh and it is used for the final calculation in this present study.

\section{RESULTS AND DISCUSSION}

\section{Concentration Distributions of Solid Phase}

Figure 3 and 4(a) to 4(e) show the simulated values of solid particles concentration distributions across vertical centreline at cross-section of the pipe outlet. Here $\alpha_{\mathrm{s}(0, y)}=\mathrm{C}\left(\mathrm{y}^{\prime}\right)$ is the predicted solid particles concentration at the outlet, $\mathrm{C}_{\mathrm{vf}}$ being solid particle efflux 
concentration, determined as the average value of particle concentration along the vertical centreline (in the y-direction), represented as:

$$
C_{v f}=\frac{1}{2 y} \int_{-y}^{+y} \alpha_{s}\left(y, Y^{\prime}\right) d y
$$

Where $\mathrm{Y}^{\prime}=\mathrm{Y} / \mathrm{D}, \mathrm{Y}$ is the height of the vertical centreline from top to bottom of pipe cross section at the outlet in the y-direction.

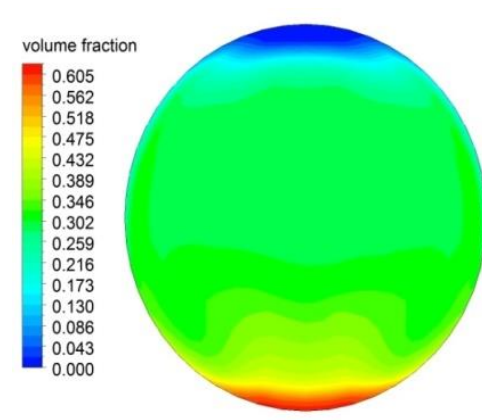

(a) $\mathrm{V}=1 \mathrm{~m} / \mathrm{s}$

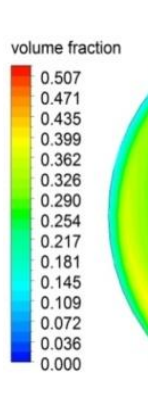

(b) $V=3 \mathrm{~m} / \mathrm{s}$
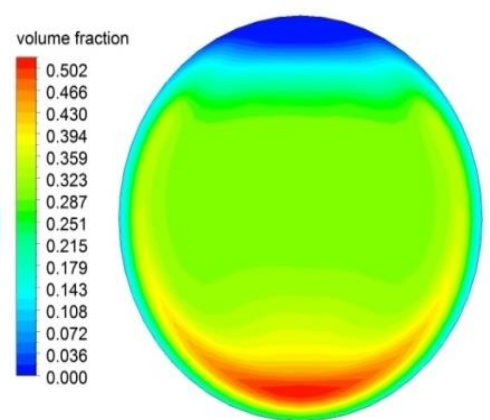

(c) $\mathrm{V}=5 \mathrm{~m} / \mathrm{s}$

Figure 3. Contours of solid concentration distribution $\left(\alpha_{\mathrm{s}}\right)$ predicted at $\mathrm{C}_{\mathrm{vf}}=0.3$.

It can be predicted from these figures that the solid particles distributions are asymmetrical along vertical plane and particles tend to settle down at the lowest portion of the pipe, and the high concentration-zone is established at the bottom half of the pipe as a result of gravity effect. It can also be observed that this asymmetrical nature decreases for the same efflux concentration value as the velocity rises. This is anticipated because at higher velocities the turbulent energy increases which causes the particle suspension. When velocity increases the particles become more suspended rather than settling down at the lowest portion the pipe. It can also be observed that the particles disperse in this fashion that their relationship with the pipe wall becomes more vivid at higher velocities. It can be noticed that the deviation of the solid particle concentration in horizontal plane becomes more observable with raise in efflux concentration and velocity; with the accumulation in efflux concentration for the same velocity, the particles become more distributed and symmetrical across the horizontal plane.

\section{Velocity Distribution}

Figure 5 shows the contours of velocities for different velocity range of $2-5 \mathrm{~m} / \mathrm{s}$ at efflux concentration $\left(\mathrm{C}_{\mathrm{vf}}\right)$ of 0.4 . Here $\mathrm{V}$ is the $\mathrm{Z}$ component of the velocity which is perpendicular to the cross section of the pipe. The velocity contours are obtained at the pipe outlet.

Figures 6(a) to 6(c) show the solid velocity distribution at different efflux concentration level viz. $0.3,0.4$ and 0.5 respectively. This can be marked that the distribution of solid velocity is parabolic and asymmetrical at the bottom of the pipe when velocity is low for the sake of greater shear force because the particles gravitate to settle down at the lowest portion of the pipe. However, the solid velocity distribution appears to be more symmetrical as the efflux concentration and velocity increases. This happens 
because as velocity and efflux concentration increases, the turbulent energy increases which provide a complete blending of fluid and solid particles, the solid particles no longer seem to be settled at pipe bottom, subsequently the distribution of velocity develops into more symmetric nature.

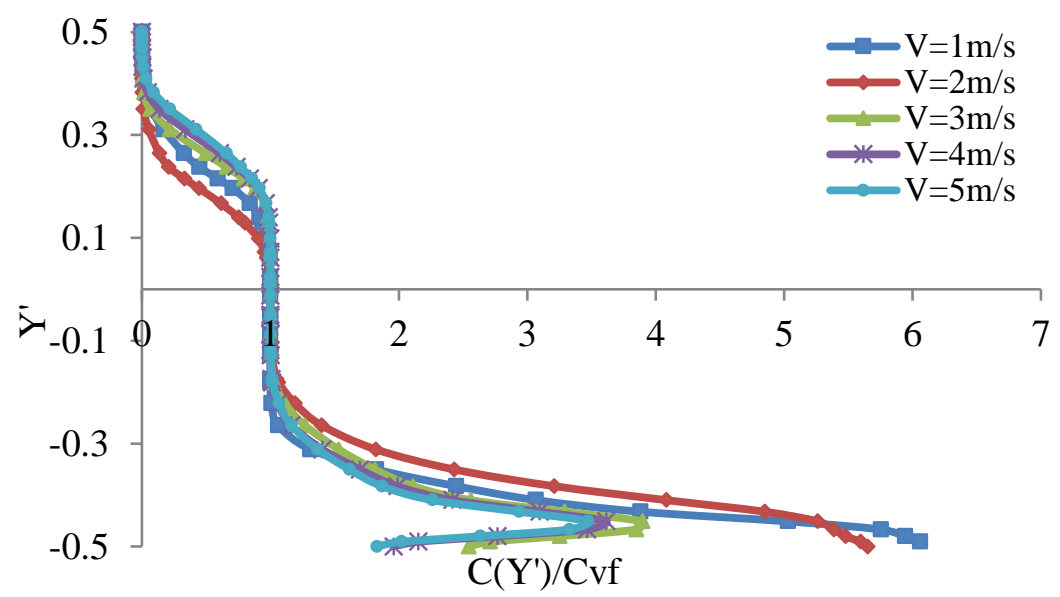

(a)

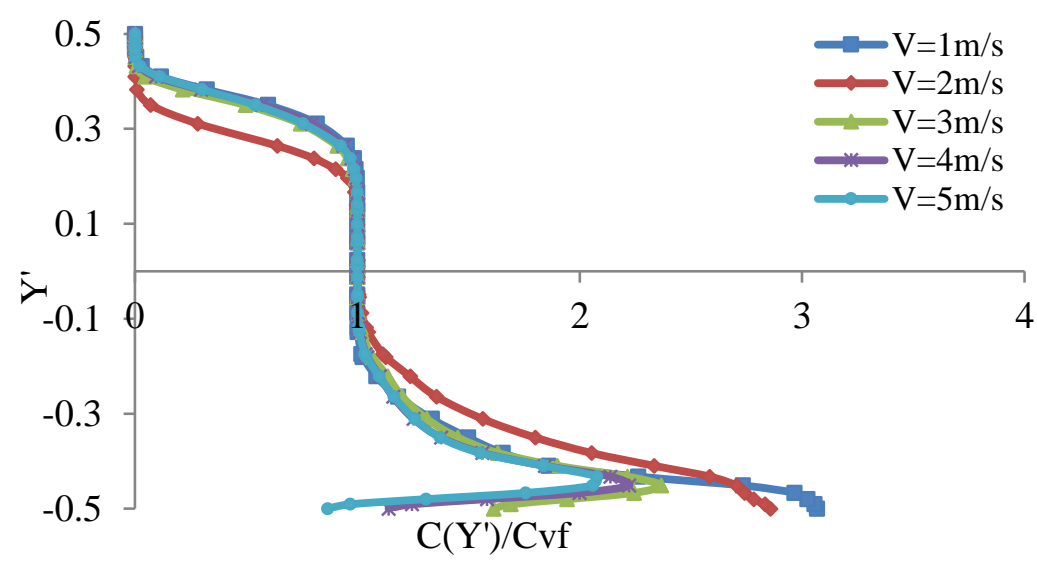

(b)

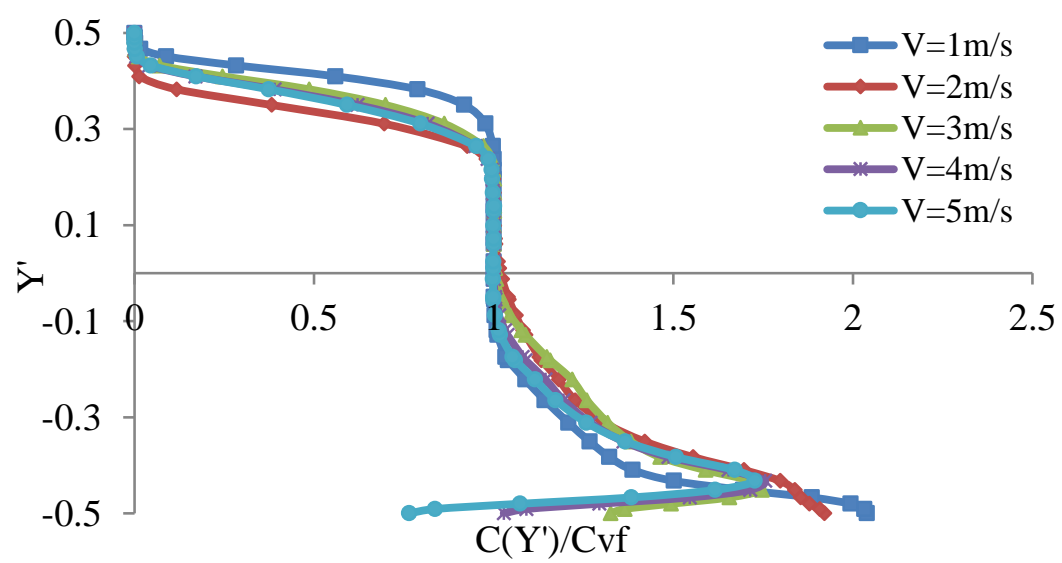

(c) 


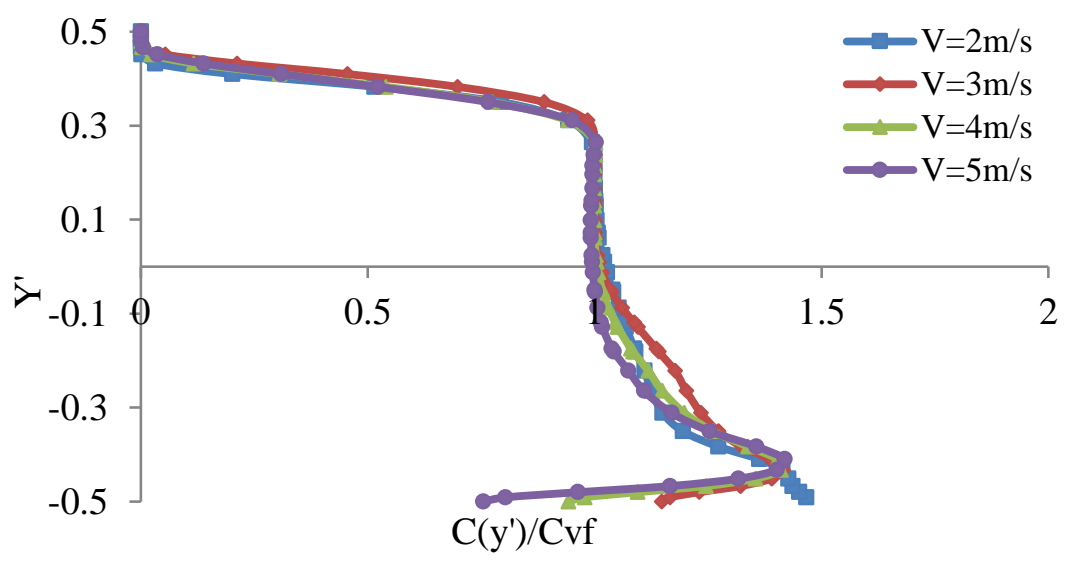

(d)

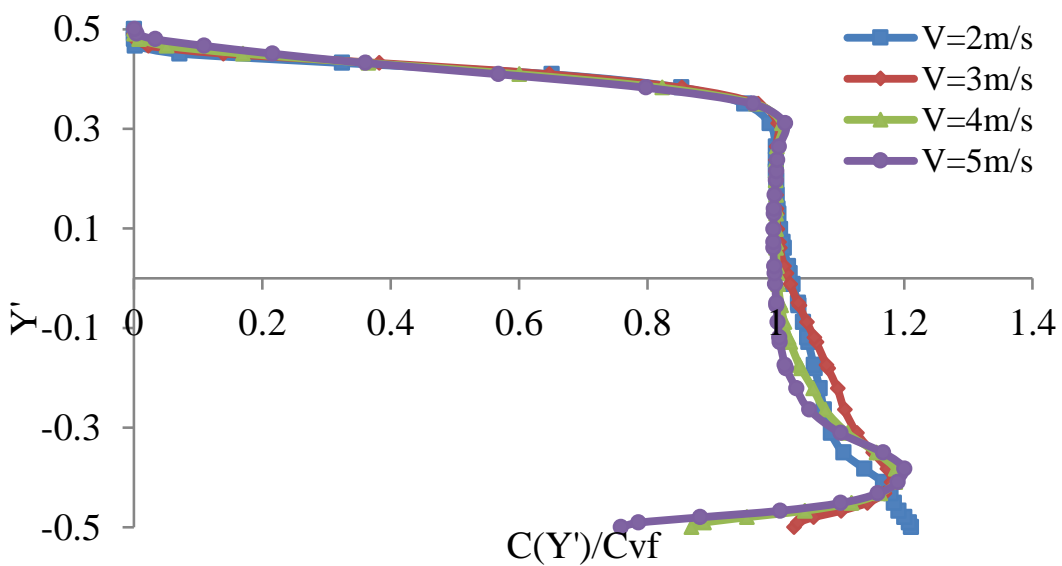

(e)

Figure 4. Plots of predicted solid concentration $\alpha_{\mathrm{s}}\left(-\mathrm{y}\right.$, y) at (a) $\mathrm{C}_{\mathrm{vf}}=0.1$, (b) $\mathrm{C}_{\mathrm{vf}}=0.2$, (c) $C_{\mathrm{vf}}=0.3$, (d) $\mathrm{C}_{\mathrm{vf}}=0.4$ and; (e) $\mathrm{C}_{\mathrm{vf}}=0.5$.

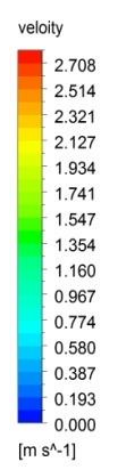

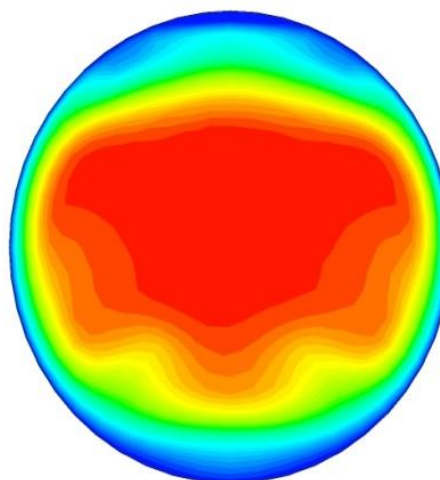

(a) $\mathrm{V}=2 \mathrm{~m} / \mathrm{s}$

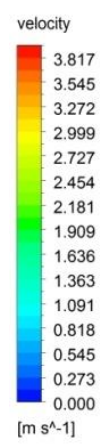

$\left[m s^{\wedge}-1\right]$

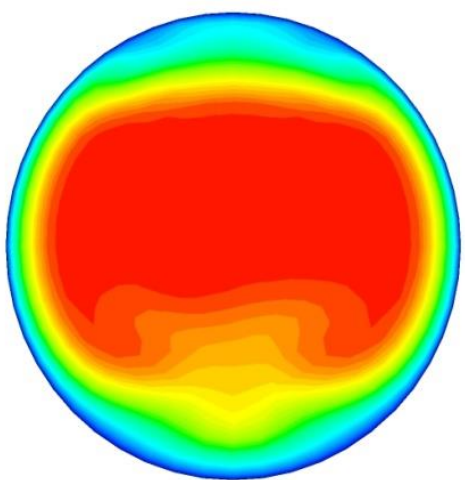

(b) $V=3 \mathrm{~m} / \mathrm{s}$ 


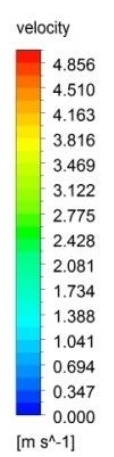

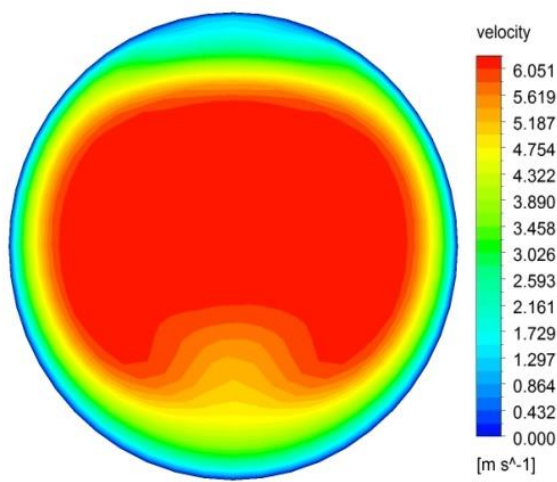

(c) $V=4 \mathrm{~m} / \mathrm{s}$

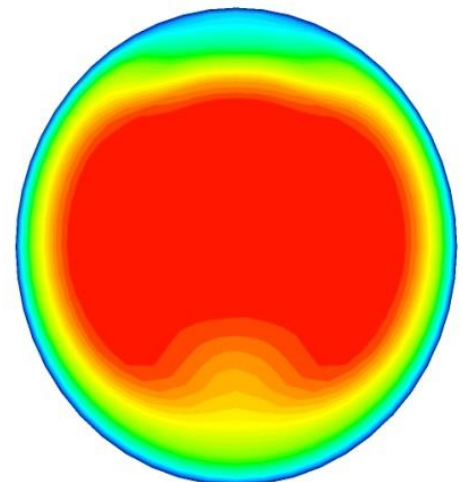

(d) $V=5 \mathrm{~m} / \mathrm{s}$

Figure 5. Contours of simulated velocity distribution (V) at $C_{v f}=0.4$.

Figure 7(a) and 7(b) show the solid particles velocity distributions across vertical centreline of a cross section of the pipe outlet from top to bottom at a given velocity viz. $4 \mathrm{~m} / \mathrm{s}$ and $5 \mathrm{~m} / \mathrm{s}$ respectively at various efflux concentration. From these figures, a remarkable change in velocity distribution can be observed. For constant velocity, as the efflux concentration rises the velocity distribution becomes more asymmetric and the position of maximum velocity shifts in the vicinity of the uppermost portion of the pipe.

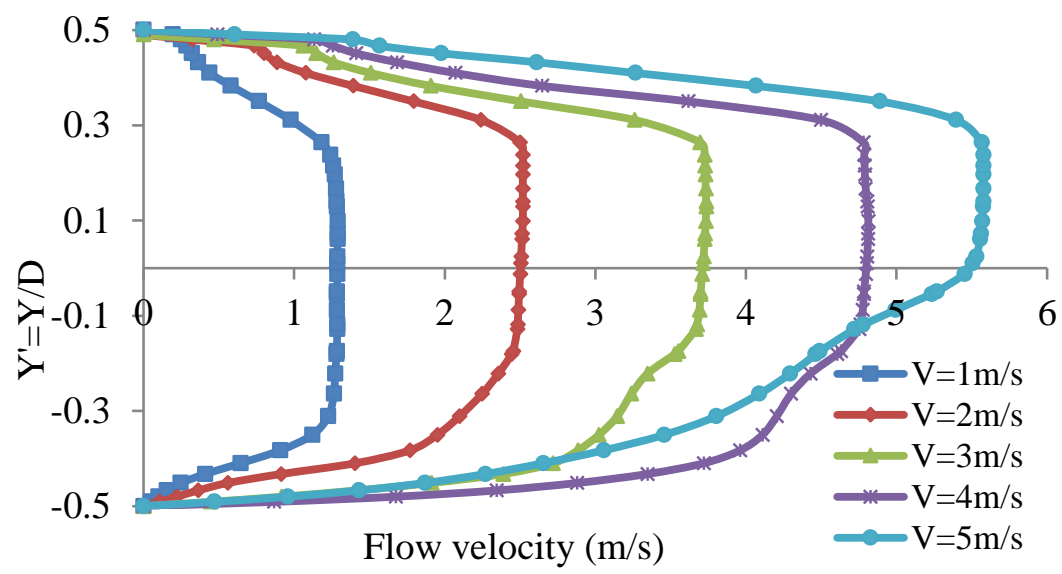

(a)

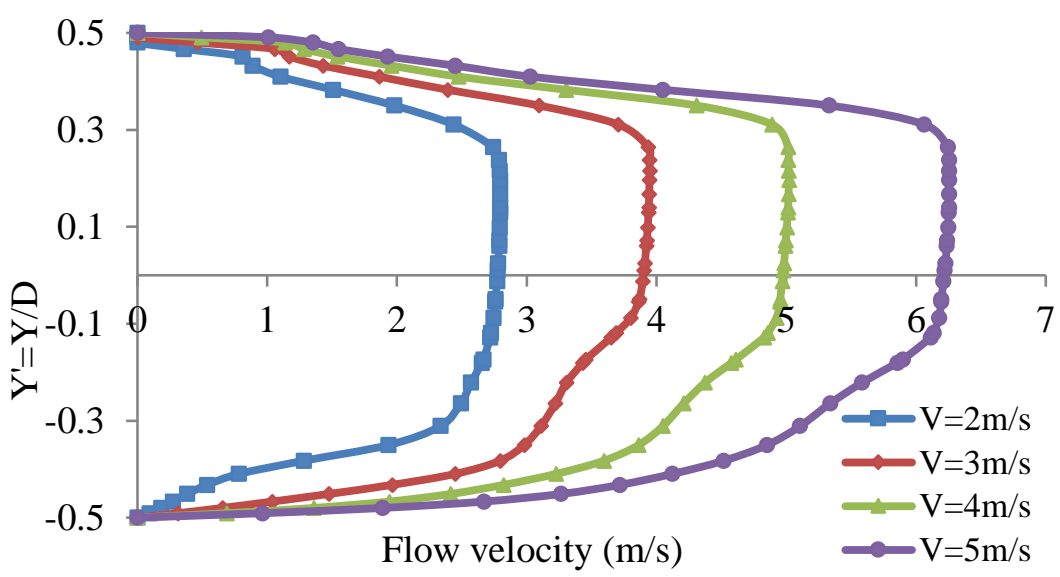

(b) 


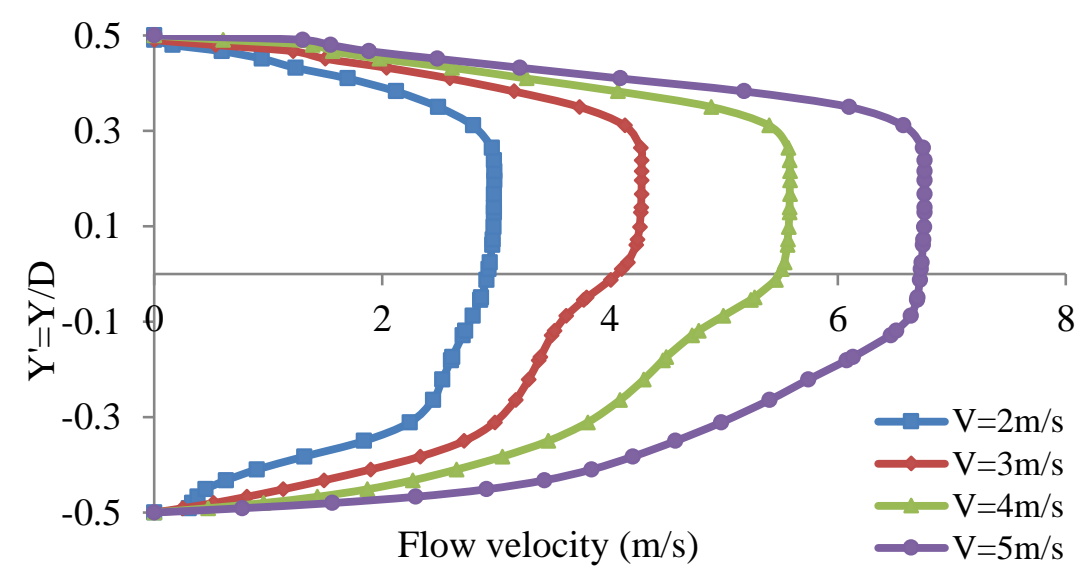

(c)

Figure 6. Plots of simulated velocity distribution (V) at (a) $\mathrm{C}_{\mathrm{vf}}=0.3$, (b) $\mathrm{C}_{\mathrm{vf}}=0.4$ and; (c) $C_{\mathrm{vf}}=0.5$.

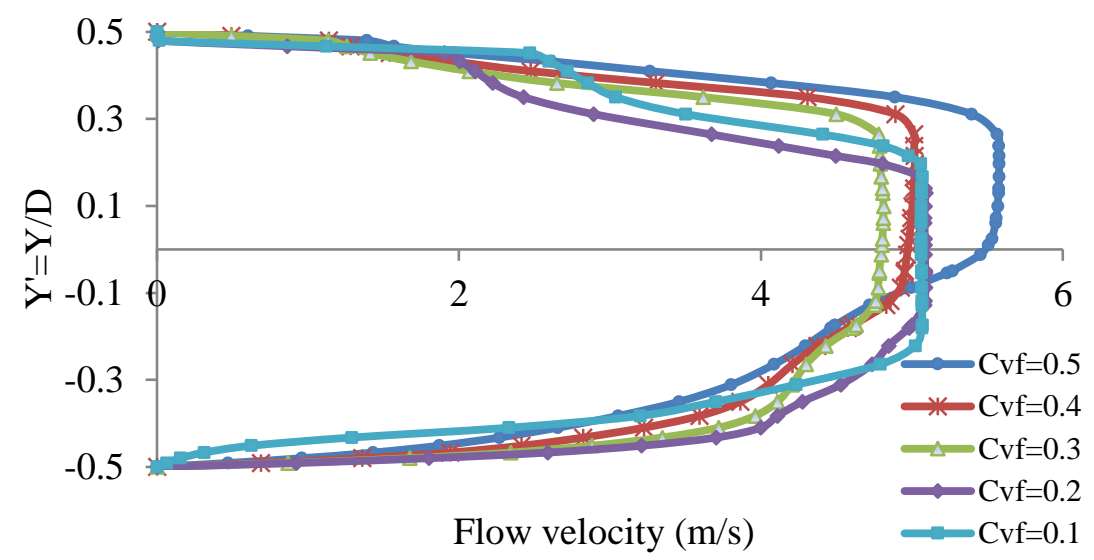

(a)

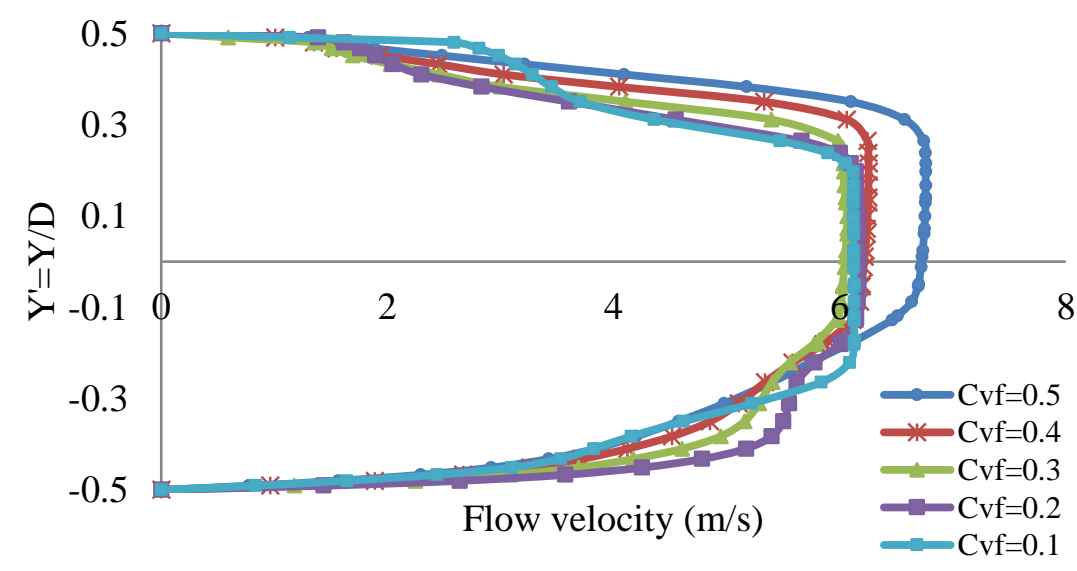

(b)

Figure 7. Plot of simulated flow velocity distribution of solid particles at given velocity (a) $\mathrm{V}=4 \mathrm{~m} / \mathrm{s}$ and; (b) $\mathrm{V}=5 \mathrm{~m} / \mathrm{s}$ and different efflux concentration. 


\section{VALIDATION OF THE STUDY}

The purpose of this investigation is to legitimise the simulated predicted outcome of the impact of solid particles concentration and flow velocity on the pressure drop of the settling slurries in a horizontal pipe. The verification is achieved by correlating simulated outcome with the experimental outcome of pressure drop available in the work of Kaushal and Tomita [18]. Figures 8(a) and 8(b) show the influence of slurry mean velocity on pressure drop for solid concentrations of 0.1 and 0.4 respectively. Differential pressure along the length $(\Delta \mathrm{P} / \mathrm{L})$ is taken on $\mathrm{Y}$-axis and means flow velocity is taken on $\mathrm{X}$-axis for plotting the graphs. For comparing the simulated and experimental results, plot digitiser software is used to extract the coordinates from the experimental results.

Figure 8 shows the analogous relation between simulated and experimental pressure drop contours at different efflux concentration level. Different trend in the development of pressure drop with an increase in velocity can be observed; generally, the increase in velocity brings around the raise in pressure drop. It can also be noticed that for a given velocity the pressure gradient rises with an increase in efflux concentration. The degree of increase in pressure drop with increase in concentration is less when velocity is low but rises abruptly at high velocities.

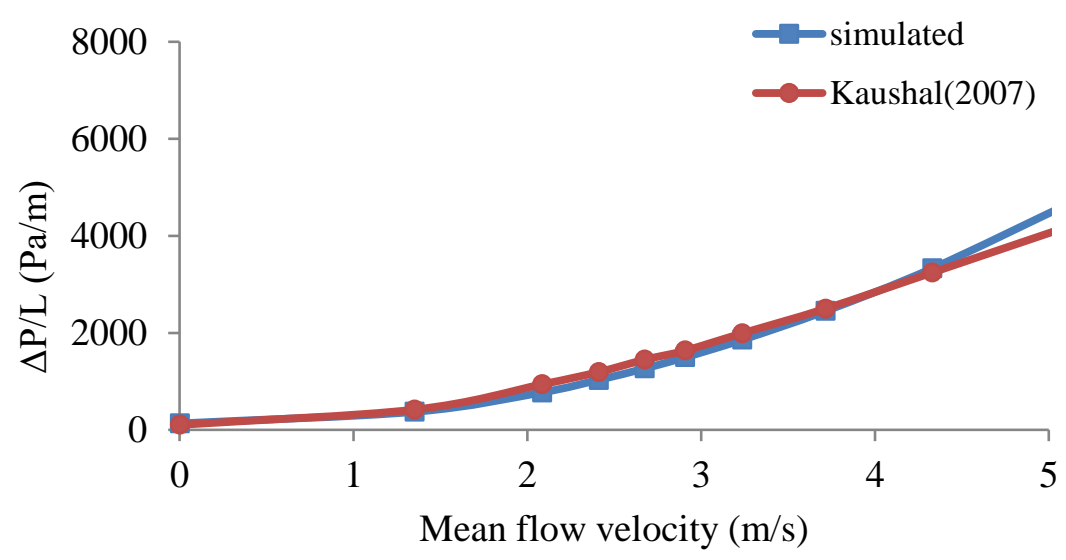

(a)

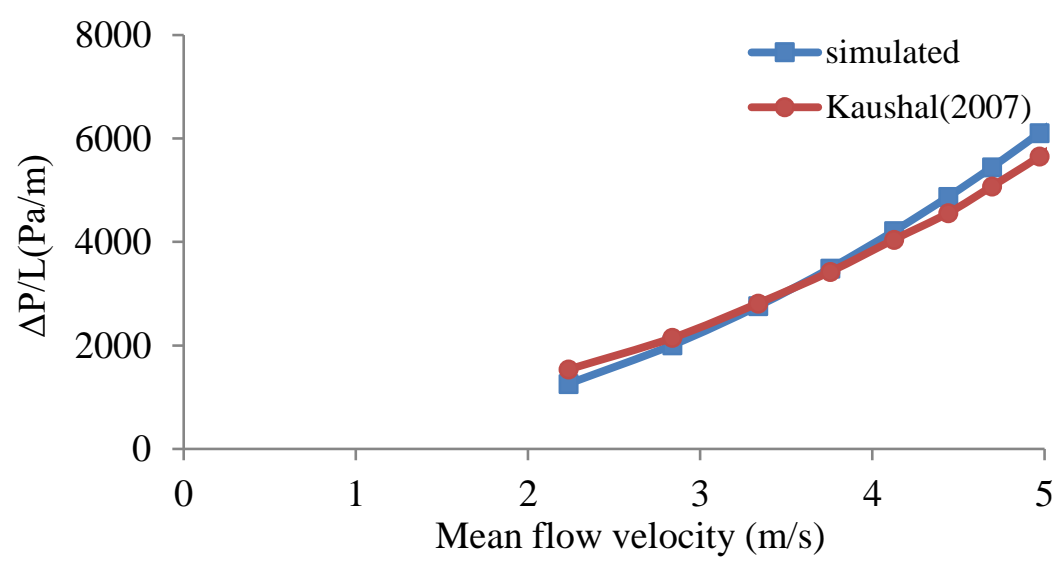

Figure 8. Comparison of simulated and experimental pressure drop overflow velocity at (a) $C_{v f}=0.1$ and; (b) $C_{v f}=0.4$. 


\section{CONCLUSION}

The proposed work presents a 3D numerical analysis of two-phase (glass beads-water) flow using CFD technique through $54.9 \mathrm{~mm}$ diameter horizontal pipe of $4 \mathrm{~m}$ length for flow velocity range of $1 \mathrm{~m} / \mathrm{s}$ to $5 \mathrm{~m} / \mathrm{s}$ and efflux concentration range of $10 \%$ to $50 \%$ (by volume) with one particle size $125 \mu \mathrm{m}$ and particle density of $2470 \mathrm{~kg} / \mathrm{m}^{3}$. A granular version of two-phase Eulerian model with RNG K- $\varepsilon$ turbulence model was adopted for the slurry flow. The particles were treated as mono- dispersed. The following conclusions can be drawn based on the current study:

i. The solid particles are asymmetrically distributed across the vertical centreline of the pipe cross-section.

ii. When the solid concentration and flow velocity is less, the higher concentration zone $(40 \%-50 \%)$ is established at the bottom half of the pipe, where the solid particles seem to be settled at the lowest portion the pipe.

iii. For a given efflux concentration when the flow velocity raises the turbulent energy increases which cause a decrease in the asymmetric distribution of the particles and particles to tend to suspend in the fluid rather than settling down at the bottom.

iv. The solid particles dispersed in this fashion that their interaction with the pipe wall becomes more vivid at higher velocities in the order of 3-5 m/s.

v. The deviation of the solid particle concentration in horizontal plane becomes more observable with raise in efflux concentration and velocity; moreover, with the accumulation in efflux concentration for the same velocity, the particles become more distributed and symmetrical across the horizontal plane.

vi. Velocity distribution is asymmetrical at the bottom part of the pipe along a vertical plane. As a consequence of the difference in density between the solid and fluid phase which leads to settling down of solid particles at the lowest portion of the pipe.

vii. With the increase in flow velocity from 1 to $5 \mathrm{~m} / \mathrm{s}$ at a given efflux concentration, the velocity distribution becomes more symmetric as the increased turbulence energy provides a proper mixing of the solid particles and fluid at higher velocities.

viii. At a given velocity as the efflux concentration increases the velocity distribution becomes more asymmetric and maximum velocity point shifts towards the top of the pipe.

The obtained results of the predetermined pressure drop are observed to be in synchronism with the experiment results. Moreover, the comparison of the simulated results proves the practical utility and high designing capability of Eulerian-Eulerian model with RNG k- $\varepsilon$ turbulence model. The work can further be extended for U-bend, vertical bend and horizontal bend pipeline designing.

\section{REFERENCES}

[1] Link JM, Lavingia NJ, Faddick RR. The economic selection of a slurry pipeline. Transportation Research Board.1974; No. Paper K-3-1.

[2] O'Brien MP. Review of the theory of turbulent flow and its relations to sediment transport. Transaction of the American Geophysical Union. 1933; 14: 487-491.

[3] Rouse H. Modern conceptions of the mechanics of fluid turbulence. Transactions of ASCE. 1937; 102: 463-505. 
[4] Kaushal DR, Sato K, Toyota T, Funatsu K, Tomita Y. Effect of particle size distribution on pressure drop and concentration profile in pipeline flow of highly concentrated slurry. International Journal of Multiphase Flow. 2005; 31(7):80923.

[5] Kaushal DR, Tomita Y. Solid concentration profiles and pressure drop in pipeline flow of multisized particulate slurries. International Journal of Multiphase Flow. 2002; 28: 1697-1717.

[6] Kaushal DR, Tomita Y. Comparative study of pressure drops in multisized particulate slurry flow through pipe and rectangular duct. International Journal of Multiphase Flow. 2003; 29: 1473-1487.

[7] Gillies RG, Shook CA. Modeling high concentration settling slurry flows. The Canadian Journal of Chemical Engineering. 2000; 78: 709-716.

[8] Gillies RG, Hill KB, Mckibben MJ, Shook CA. Solids transport by laminar Newtonian flows. Powder Technology. 1999; 104: 269-277.

[9] Gillies RG, Shook CA, Wilson KC. An improved two layer model for horizontal slurry pipeline flow. The Canadian Journal of Chemical Engineering. 1991; 69: 173-178.

[10] Roco MC, Shook CA. Computational methods for coal slurry pipeline with heterogeneous size distribution. Powder Technology. 1984; 39: 159-176.

[11] Roco MC, Shook CA. Modeling of slurry flow: The effect of particle size. The Canadian Journal of Chemical Engineering. 1983; 61: 494-503.

[12] Seshadri V, Malhotra RC, Sundar K.S. Concentration and size distribution of solids in a slurry pipeline. In: Proc. 11th Nat. Conference on Fluid mechanics and fluid power, B.H.E.L., Hyderabad; 1982.

[13] Seshadri V. Basic process design for a slurry pipeline. In: Proc. The Short Term Course on Design of pipelines for transporting liquid and solid materials, IIT, Delhi; 1982.

[14] Karabelas AJ. Vertical distribution of dilute suspensions in turbulent pipe flow. AIChE Journal. 1977; 23: 426-434.

[15] Shook CA, Daniel SM, Scott JA, Holgate JP. Flow of suspensions in pipelines. The Canadian Journal of Chemical Engineering. 1968; 46: 238-244.

[16] Shook CA, Daniel SM. Flow of suspensions of solids in pipeline: I. Flow with a stable stationary deposit. The Canadian Journal of Chemical Engineering. 1965; 43: $56-72$.

[17] Wilson KC, Clift R, Sellgren A. Operating points for pipelines carrying concentrated heterogeneous slurries. Powder Technology. 2002; 123: 19-24.

[18] Kaushal DR, Tomita Y. Experimental investigation for near-wall lift of coarser particles in slurry pipelines using $\gamma$-ray densitometer. Powder technology. 2007; 172(3): 177-187.

[19] Ghanta KC, Purohit NK. Pressure drop prediction in hydraulic transport of bidispersed particles of coal and copper ore in pipeline. The Canadian Journal of Chemical Engineering. 1999; 77: 127-131.

[20] Mishra R, Singh SN, Seshadri V. Improved model for prediction of pressure drop and velocity field in multisized particulate slurry flow through horizontal pipes. Powder Handling and Processing Journal. 1998; 10: 279-289.

[21] Sundqvist A, Sellgren A, Addie G. Slurry pipeline friction losses for coarse and high density products. Powder Technology. 1996; 89: 19-28.

[22] Doron P, Granica D, Barnea D. Slurry flow in horizontal pipes-experimental and modeling. International Journal of Multiphase Flow. 1987; 13: 535-547. 
[23] Wasp EJ, Aude TC, Kenny JP, Seiter RH, Jacques RB. Deposition velocities, transition velocities and spatial distribution of solids in slurry pipelines. In: Proc. Hydro transport 1, BHRA Fluid Engineering. 1970; 4.2: 53-76.

[24] Zambrano H, Sigalotti LDG, Klapp J, Peña-Polo F, Bencomo A. Heavy oil slurry transportation through horizontal pipelines: Experiments and CFD simulations. International Journal of Multiphase Flow. 2017; 91: 130-141.

[25] Singh J, Kumar S, Singh JP, Kumar P, Mohapatra SK. CFD modeling of erosion wear in pipe bend for the flow of bottom ash suspension. Particulate Science and Technology. 2018; 1-11.

[26] Wang J, Wang S, Zhang T, Battaglia F. 2017 Mathematical and experimental investigation on pressure drop of heterogeneous ice slurry flow in horizontal pipes. International Journal of Heat and Mass Transfer. 2017; 108: 2381-2392.

[27] Liu J, BaKeDaShi W, Li Z, Xu Y, Ji W, Zhang C, Cui G, Zhang R. Effect of flow velocity on erosion-corrosion of 90-degree horizontal elbow. Wear. 2017; 376:516-525.

[28] Kaushal DR, Thinglas T, Tomita Y, Kuchii S, Tsukamoto H. CFD modeling for pipeline flow of fine particles at high concentration. International Journal of Multiphase Flow. 2012; 43:85-100.

[29] Chen L, Duan Y, Pu W, Zhao C. CFD simulation of coal-water slurry flowing in horizontal pipelines. Korean journal of chemical engineering. 2009; 26(4):11441154

[30] Lin CX, Ebadian MA. A numerical study of developing slurry flow in the entrance region of a horizontal pipe. Computers \& Fluids. 2008; 37(8):965-974.

[31] Nabil T, El-Sawaf I, El-Nahhas K. Computational fluid dynamics simulation of the solid-liquid slurry flow in a pipeline. InProc. 17th International Water Technologies Conference IWTC17 2013; Vol. 57.

[32] Gopaliya MK, Kaushal DR. Modeling of sand-water slurry flow through horizontal pipe using CFD. Journal of Hydrology and Hydromechanics. 2016; 64(3): 261-272.

[33] Messa GV, Malin M, Malavasi S. Numerical prediction of fully-suspended slurry flow in horizontal pipes. Powder Technology. 2014; 256: 61-70.

[34] Gopaliya MK, Kaushal DR. Analysis of effect of grain size on various parameters of slurry flow through pipeline using CFD. Particulate Science and Technology. 2015; 33(4):369-384.

[35] Ekambara K, Sanders RS, Nandakumar K, Masliyah JH. Hydrodynamic simulation of horizontal slurry pipeline flow using ANSYS-CFX. Industrial \& Engineering Chemistry Research. 2009; 48(17):8159-8171.

[36] Kaushal DR, Kumar A, Tomita Y, Kuchii S, Tsukamoto H. Flow of monodispersed particles through horizontal bend. International Journal of Multiphase Flow. 2013; 52:71-91.

[37] Njobuenwu DO, Fairweather M. Modelling of pipe bend erosion by dilute particle suspensions. Computers \& Chemical Engineering. 2012; 42:235-247.

[38] Bartosik A. Application of rheological models in prediction of turbulent slurry flow. Flow, turbulence and combustion. 2010; 84(2):277-293.

[39] Furlan JM, Mundla V, Kadambi J, Hoyt N, Visintainer R, Addie G. Development of A-scan ultrasound technique for measuring local particle concentration in slurry flows. Powder technology. 2012; 215:174-184.

[40] Peng W, Cao X. Numerical simulation of solid particle erosion in pipe bends for liquid-solid flow. Powder Technology. 2016; 294:266-279. 
[41] Vaishnav AH, Chandel S. Numerical Analysis of High Concentration Coal Ash Slurry Flow through Pipelines. 2018.

[42] Onokoko L, Poirier M, Galanis N, Poncet S. Experimental and numerical investigation of isothermal ice slurry flow. International Journal of Thermal Sciences. 2018; 126:82-95.

[43] Lun KK, Stuart S, Jeffrey D, Chepurniy N. Kinetic theories for granular flow: Inelastic particles in couette flow and slightly inelastic particles in a general flowfield . Journal of Fluid Mechanics. 1984; 140: 223-256. 